\title{
Reações teciduais induzidas pela abraçadeira autoestática de náilon em ligaduras de pedículos ovarianos
}

\author{
Luiz Fernando Moraes Moreira ${ }^{1}$ \\ Luiz Fernando Souza Rodrigues ${ }^{2}$ \\ Ednaldo Silva Filho ${ }^{1}$ \\ Washington Luiz Assunção Pereira ${ }^{1}$ \\ Marcella Katheryne Marques Bernal ${ }^{1 *}$ \\ Sheila Canevese Rahal ${ }^{2}$ \\ Frederico Ozanan Barros Monteiro ${ }^{1}$ \\ ${ }^{1}$ Universidade Federal Rural da Amazônia \\ Avenida Presidente Tancredo Neves, 2501, Terra Firme, CEP 66.077-830, Belém - PA, Brasil \\ ${ }^{2}$ Universidade Estadual Paulista, São Paulo - SP, Brasil \\ * Autor para correspondência \\ mkbernalfh@gmail.com
}

Submetido em 25/07/2017

Aceito para publicação em 30/01/2018

\section{Resumo}

Objetivou-se avaliar as reações teciduais induzidas pela abraçadeira autoestática de náilon na oclusão dos pedículos ovarianos, por meio de avaliação macroscópica e histológica. Utilizaram-se 45 fêmeas caninas, sem raça definida, clinicamente sadias, com idade média de 31,11 $\pm 14,26$ meses e peso médio de 11,26 $\pm 4,7 \mathrm{~kg}$. Todas foram submetidas à ovariosalpingohisterectomia pela técnica minimamente invasiva. Os animais foram divididos aleatoriamente em três grupos com 15 animais cada, que foram avaliados no pós-cirúrgico imediato e aos 30 (G1), 60 (G2) e 90 dias (G3) de pós-operatório. Ao exame histológico dos pedículos contendo as abraçadeiras foi observada, no $30^{\circ}$ dia de pós-operatório, reação inflamatória crônica com macrófagos, células gigantes e fibroplasia. No $60^{\circ}$ dia, tecido conjuntivo totalmente organizado e em modelação, e presença de linfócitos e polimorfonucleares. No $90^{\circ}$ dia de pós-operatório, tecido conjuntivo maduro totalmente organizado com áreas em modelação, macrófagos e linfócitos. As abraçadeiras promovem reação inflamatória que deve ser considerada no momento da aplicação do material, visto a possibilidade de interferência com outras estruturas.

Palavras-chave: Fêmeas caninas; Histologia; Ovariosalpingohisterectomia

\section{Abstract}

Tissue reactions induced by nylon cable tie used to clamp ovarian pedicles. The aim of this study was to evaluate the tissue reactions induced by nylon cable tie by using macroscopic and histological evaluations. Forty-five clinically healthy crossbreed female dogs, $31.11 \pm 14.26$ months old and with a body weight of 11.26 $\pm 4.7 \mathrm{~kg}$, underwent ovariohysterectomy using a minimally invasive procedure. The dogs were randomly divided 
into three groups of 15 animals each and were evaluated preoperatively, and at 30 (G1), 60 (G2) and 90 days (G3) after surgery. The histological examination of the pedicles containing the nylon cable ties, collected from five animals in each group, showed a chronic inflammatory reaction with the presence of macrophages, giant cells and fibroplasia on the $30^{\text {th }}$ postoperative day. Well-organized connective tissue and presence of lymphocytes and polymorphonuclear leukocytes were seen on the $60^{\text {th }}$ postoperative day, and mature connective tissue and presence of macrophages and lymphocytes were seen at 90 days. Nylon cable ties induce an inflammatory reaction, which should be considered due to the risk of interference with surrounding structures.

Key words: Female dog; Histology; Ovariohysterectomy

\section{Introdução}

Medidas de controle sanitário e populacional de cães e gatos têm sido aplicadas, seja por meio de intervenção de cunho legislativo e educacional, ou por medidas mais extremas, tais como intervenções cirúrgicas ou mesmo eutanásia (MAHLOW; SLATER, 1996; LIMA; LUNA, 2012). Entre os procedimentos cirúrgicos de controle populacional que apresentam alta eficácia, destaca-se a ovariosalpingohisterectomia, especialmente se efetuada por técnicas minimamente invasivas como a videocirurgia ou cirurgia laparoscópica, com menor manipulação e exposição de tecidos e órgãos, menor tempo cirúrgico e, consequentemente, baixa taxa de morbidade (ATAIDE et al., 2010; LIMA et al., 2010; LIMA; LUNA, 2012).

Associada a essa técnica, conta-se atualmente com a utilização de abraçadeiras autoestáticas de náilon na oclusão do complexo arteriovenosos ovarianos e coto uterino como uma possível alternativa de baixo custo e de fácil aplicação (BARROS et al., 2009; COSTA NETO et al., 2009; LIMA et al., 2010). Contudo, apesar desse material ter se mostrado resistente à tração, antes e após esterilização por autoclavagem (MIRANDA et al., 2006), e aparentemente mostrar boa evolução pósoperatória (BARROS et al., 2009; COSTA NETO et al., 2009; LIMA et al., 2010), complicações já foram descritas na literatura (MESQUITA et al., 2015).

Recentemente, o uso de abraçadeira de náilon foi desaconselhado pelo Conselho Federal de Medicina Veterinária por apresentar elevado risco de formações granulomatosas e fistulações (CRMV-SP, 2015). Sendo assim, ainda que a técnica cirúrgica esteja bem definida, faltam estudos quanto ao uso da abraçadeira no que diz respeito à segurança e à biocompatibilidade.
Com base no exposto, o presente trabalho teve por objetivos avaliar as reações teciduais induzidas pela abraçadeira autoestática de náilon na oclusão dos pedículos ovarianos em cadelas.

\section{Material e Métodos}

O estudo foi realizado entre março de 2011 e fevereiro de 2013 no Hospital Veterinário "Professor Mário Dias Teixeira" do Instituto da Saúde e Produção Animal da Universidade Federal da Amazônia (UFRA), com aprovação pela Comissão de Ética no Uso de Animais (CEUA/UFRA protocolo 23084007182/2012-12).

Foram utilizadas 45 cadelas clinicamente sadias, sem raça definida, com idade média de 31,11 $\pm 14,26$ meses e peso médio de $11,26 \pm 4,7 \mathrm{~kg}$, submetidas à ovariosalpingohisterectomia, utilizando a abraçadeira autoestática.

As fêmeas foram selecionadas com base no exame clínico geral e hemograma completo. Foram agrupadas aleatoriamente em três grupos com 15 animais cada, que foram avaliados no pós-cirúrgico imediato e aos 30 (G1), 60 (G2) e 90 dias (G3) de pós-operatório, por meio de exames ultrassonográficos, macro e microscopia. Todos os animais foram submetidos ao jejum alimentar de $12 \mathrm{~h}$ e hídrico de $2 \mathrm{~h}$. Adicionalmente foram aplicados penicilina benzatina $(40.000 \mathrm{UI} / \mathrm{kg})$ via intramuscular e meloxican $(0,2 \mathrm{mg} / \mathrm{kg})$, por via subcutânea, entre 30 e 60 minutos antes da intervenção cirúrgica.

Os procedimentos pré-anestésicos consistiram na aplicação por via intramuscular da combinação de acepromazina $(0,05 \mathrm{mg} / \mathrm{kg})$, morfina $(0,5 \mathrm{mg} / \mathrm{kg})$ e cloridrato de xilazina $(0,5 \mathrm{mg} / \mathrm{kg})$. Quinze minutos após, foi realizada a venóclise pela punção da veia cefálica, com a utilização de escalpe (no 23$)$, e instituída 
fluidoterapia com solução fisiológica $(10 \mathrm{~mL} / \mathrm{kg} / \mathrm{h})$. A anestesia foi induzida e mantida com cetamina (10 $\mathrm{mg} / \mathrm{kg})$ e diazepam $(0,25 \mathrm{mg} / \mathrm{kg})$, por via endovenosa. Quando necessário, a anestesia foi complementada com cetamina ( $5 \mathrm{mg} / \mathrm{kg}$ ) pela mesma via.

A ovariosalpingohisterectomia foi iniciada pela incisão da pele de 2 a $3 \mathrm{~cm}$ na área retro umbilical (aproximadamente $5 \mathrm{~cm}$ caudal a cicatriz umbilical). Em seguida, com auxílio de tesoura romba e pinça dente de rato, foi incisado o tecido adiposo subcutâneo, com posterior elevação da parede muscular em conjunto com a linha alba, a qual foi incisada. Uma vez acessada a cavidade abdominal, foi introduzido o gancho de castração para localização e exposição do corno e de seu respectivo ovário.

Quando necessário, foi realizada a ruptura do ligamento suspensor do ovário. Na sequência, foi realizada a ligadura do complexo arteriovenosos com abraçadeira autoestática de náilon $100 \times 2,5 \mathrm{~mm}$, de cor natural (marca Bemfixa), aplicada com o sistema de trava em posição medial. O pedículo foi então incisado em torno de $3 \mathrm{~mm}$ acima da abraçadeira e o seu excesso foi seccionado próximo ao sistema de trava, com alicate de aço inox. Procedimento semelhante foi aplicado ao pedículo contralateral.

Para exposição do corpo uterino e cérvix, os cornos uterinos foram levemente tracionados e o ligamento largo foi seccionado com tesoura romba. A ligadura do corpo uterino foi realizada acima da cérvix, com o sistema de trava da abraçadeira voltado para uma das laterais, com o corte do excesso próximo ao sistema de trava.

A síntese da parede abdominal foi realizada com padrão de sutura tipo Sultan, com fio mononáilon agulhado (n- 2-0 ou 3-0), de acordo com o porte do animal, sendo o mesmo padrão de sutura aplicado no tecido subcutâneo para redução do espaço morto. A pele foi aproximada com pontos isolados tipo Wolff, empregando mononáilon agulhado. O tempo cirúrgico foi aferido contando do início da incisão da pele até o término da sutura, por meio de cronômetro digital. As abraçadeiras tinham sido esterilizadas em autoclave $\left(133^{\circ} \mathrm{C}\right.$ por 30 minutos).

Para o pós-operatório foi prescrito como analgésico a dipirona sódica $(25 \mathrm{mg} / \mathrm{kg})$, via oral, a cada $12 \mathrm{~h}$ por 3 dias. Os pontos cutâneos foram removidos no décimo dia de pós-operatório e a ferida cirúrgica avaliada quanto à presença ou ausência de sinais de inflamação, infecção ou deiscência.

Para realização dos exames histopatológicos, os animais receberam a mesma técnica de analgesia e anestesia anteriormente relatada. A colheita do material foi realizada aos 30, 60 e 90 dias, respectivamente nos Grupos 1, 2 e 3, por meio de sorteio de 5 animais de cada Grupo. Para tanto, o abdome foi acessado como descrito previamente e foi bilateralmente removido um segmento de pedículo ovariano com a respectiva abraçadeira. Antes da remoção, foi feita análise macroscópica dos pedículos para identificação de aderências na região de implantação da abraçadeira. Para evitar hemorragias foi aplicada nova abraçadeira abaixo da existente, antes da excisão dos tecidos.

O material coletado foi fixado em solução de formalina $10 \%$ tamponada e remetido ao laboratório de patologia para processamento e cortes histológicos, que foram corados pela hematoxilina e eosina (HE). A análise histológica avaliou a presença de neovascularização, tecido de granulação, presença de células inflamatórias polimorfonucleares e mononucleares e tecido de reparação cicatricial.

Os resultados foram submetidos ao teste quiquadrado em tabela de contingência $2 \times 3$ e ao Teste Exato de Fisher. Considerou-se o nível de significância de 5\%.

\section{Resultados}

Pela análise macroscópica, aos 30 dias de pósoperatório, a maioria dos pedículos apresentavam aderências do omento maior, $80 \%$ para o direito e $60 \%$ para o esquerdo, e as abraçadeiras estavam recobertas por cápsula tecidual delgada. Aos 60 dias de pós-cirúrgico, a maioria dos pedículos mostrava aderências do omento, $60 \%$ para o direito e $100 \%$ para o esquerdo.

Em três pedículos as abraçadeiras encontravam-se recobertas por cápsula de tecido mais volumoso e nos demais por fina cápsula tecidual. Noventa dias após, as abraçadeiras apresentaram aderências do omento maior, com cápsula tecidual mais volumosa esbranquiçada característica de tecido de cicatrização. Entretanto, não 
foram detectadas aderências de órgãos aos pedículos. Não houve diferença significativa $(p>0,05)$ entre os pedículos direito e esquerdo, com relação às aderências do omento maior e os períodos de observação (Tabela 1).

Ao exame microscópico (Figura 1), realizado na área de contato com a abraçadeira, observou-se, aos 30 dias de pós-operatório, ocorrência de tecido adiposo em reabsorção, reação inflamatória crônica com macrófagos, células gigantes e fibroplasia, e trombo organizado com neovascularização. Havia também tecido de granulação; neovascularização; vasos com paredes fibrosadas e espessadas, além de luz diminuída com áreas de fibrose

TABELA 1: Achados histológicos relacionados à aplicação de abraçadeiras autoestáticas de náilon nos pedículos ovarianos direito e esquerdo (POD e POE) de cadelas submetidas à ovariosalpingohisterectomia, aos 30, 60 e 90 dias pós-cirúrgico.

\begin{tabular}{lcccccc}
\hline \multirow{2}{*}{ Achados histológicos } & \multicolumn{2}{c}{$\mathbf{3 0}$ dias (\%) } & \multicolumn{2}{c}{$\mathbf{6 0}$ dias (\%) } & \multicolumn{2}{c}{$\mathbf{9 0}$ dias (\%) } \\
\cline { 2 - 7 } & POE & POD & POE & POD & POE & POD \\
\hline Tecido de granulação & 60 & 60 & - & - & - & - \\
Trombose & 40 & 60 & - & - & - & - \\
Fibrose vascular & 40 & 80 & 20 & 20 & - & 40 \\
Neovascularização & 40 & 60 & - & - & - & - \\
Remodelação cicatricial & 100 & 100 & 100 & 100 & 100 & 100 \\
Inflamação & 80 & 80 & 80 & 60 & 40 & 60 \\
Granuloma & - & - & 20 & 20 & - & - \\
\hline
\end{tabular}

FIGURA 1: Fotomicrografia do pedículo ovariano na área de contato com a abraçadeira após 30 dias. (A) Tecido fibroso formado na área de contato com a braçadeira (setas grossas). Presença de tecido adiposo em processo de reabsorção (1). Obj. 4x. (B) Tecido adiposo do pedículo ovariano. Reação inflamatória crônica com macrófagos (2), célula gigante (seta fina) e fibroplasia (3); H.E., Obj. 10x. (C) Veia do tecido original apresentando trombo em organização com neovascularização (4); H.E., Obj. 40x. (D) Presença de tecido conjuntivo com numerosos vasos neoformados. H.E., Obj. 10x.

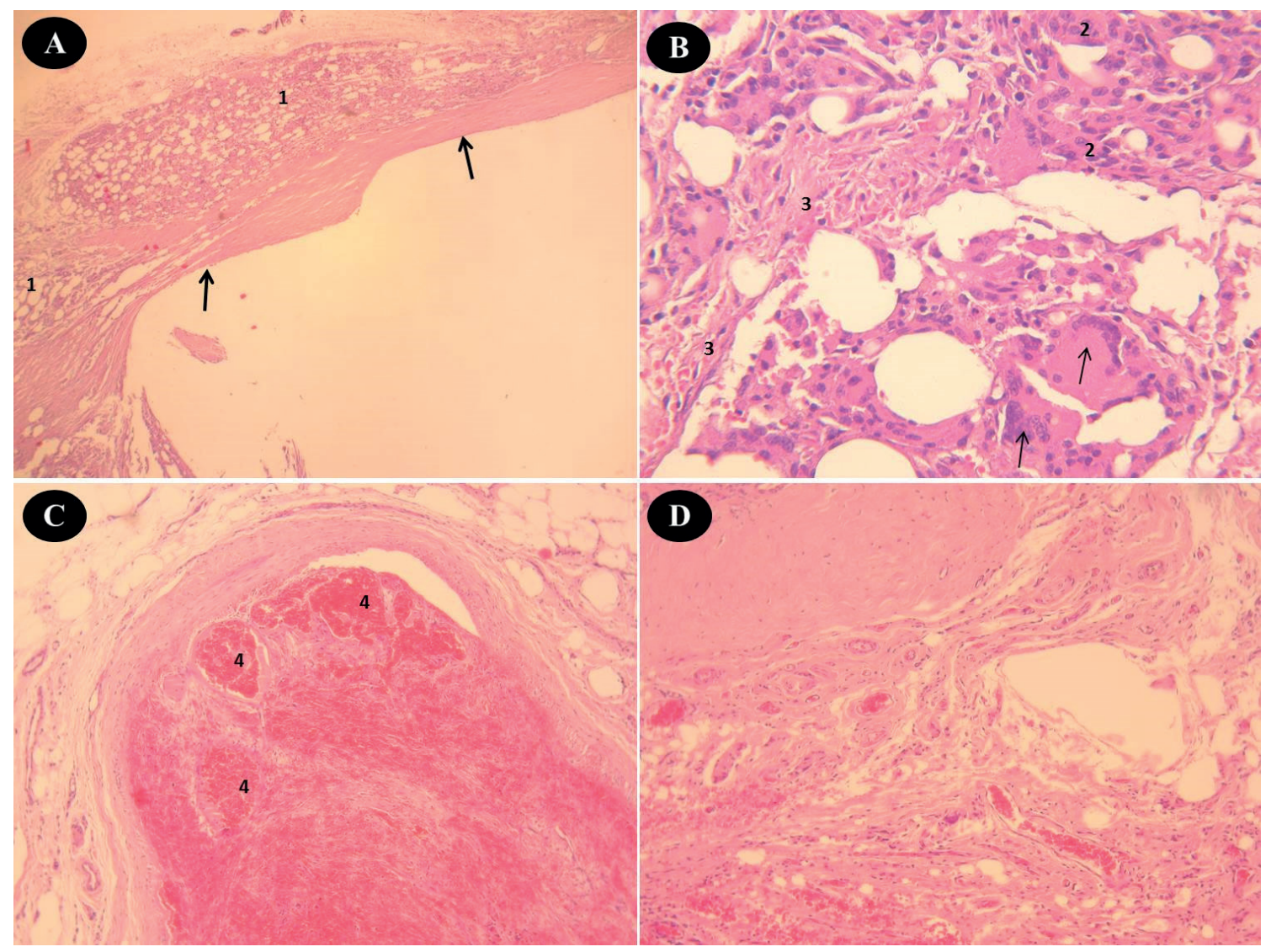


em tecido adiposo. Notaram-se ainda presença de macrófagos, alguns de aspecto espumoso, linfócitos, polimorfonucleares e de raras células gigantes tipo corpo estranho, tecido conjuntivo em modelação e tecido conjuntivo maduro.

Histologicamente, aos 60 dias de pós-operatório (Figura 2 A e 2 B), os pedículos apresentaram, na região de contato, tecido conjuntivo totalmente organizado e em modelação, e presença de linfócitos e polimorfonucleares no tecido adiposo que se localizava em torno do tecido conjuntivo. Verificou-se também a presença rara de granuloma, especificamente em uma amostra; células gigantes; vasos com paredes espessadas e luz diminuída; fibrose em tecido adiposo e muitos fibroblastos em tecido conjuntivo neoformado.

Aos 90 dias pós-cirúrgico (Figura 3 A e 3 B), observaram-se tecido conjuntivo maduro totalmente organizado com áreas em modelação, macrófagos e linfócitos, ausência de tecido de granulação. No tecido adiposo havia presença de macrófagos espumosos e, em somente uma amostra analisada, encontraram-se células gigantes tipo corpo estranho e vasos com paredes fibrosadas.

FIGURA 2: Fotomicrografia do pedículo ovariano na área de contato com a abraçadeira após 60 dias. (A e B) Tecido conjuntivo organizado (setas) envolvendo a área da braçadeira (*). (B) O tecido conjuntivo adiposo manifesta reação inflamatória (1). H.E., Obj. 4x.
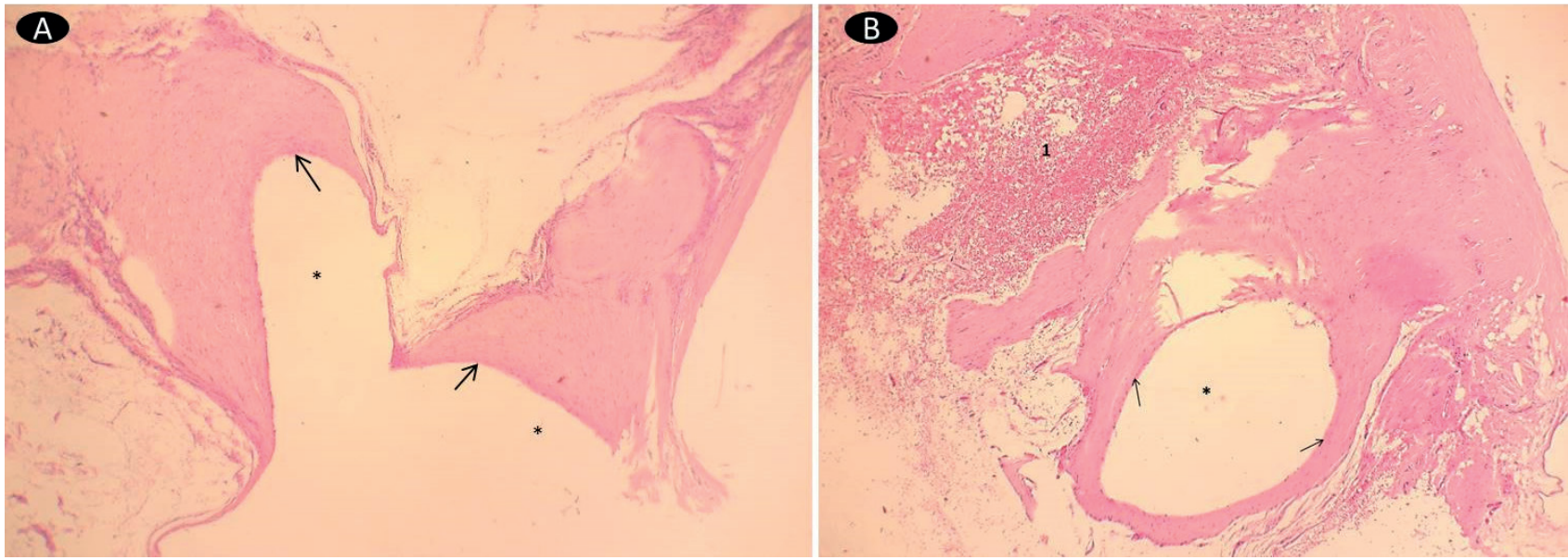

FIGURA 3: Fotomicrografia do pedículo ovariano na área de contato com a abraçadeira após 90 dias. (A) Tecido fibroso formado na área de contato com a abraçadeira (setas). Na extensão, presença de reação inflamatória menos intensa (1), comparada aos 60 dias. H.E., Obj. 4x. (B) Tecido fibroso formado na área de reabsorção de gordura contendo macrófagos espumosos (setas). H.E., Obj. 40x.
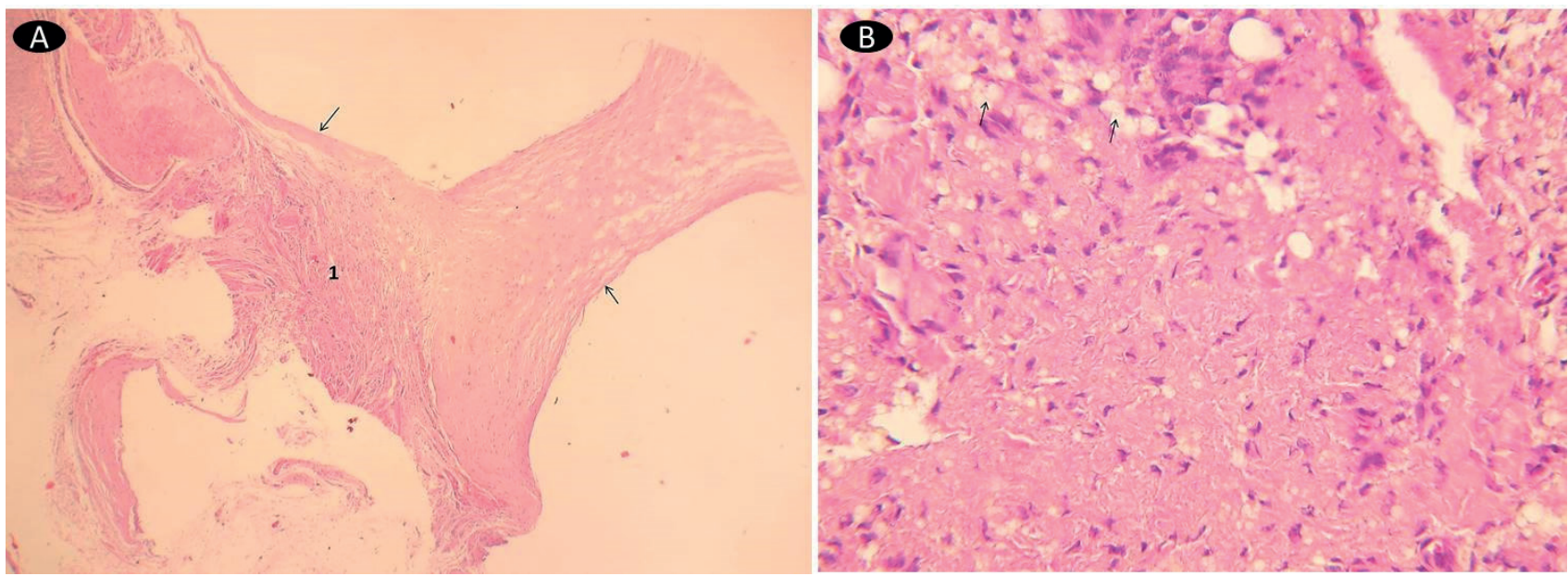


\section{Discussão}

A atividade prática deste estudo foi realizada antes da publicação de recomendação do CFMV em que desaconselha a utilização da abraçadeira autoestática de náilon em cirurgias de castração. Dessa forma, é importante frisar que não contrariou o parecer técnico publicado em 15 de abril de 2015. Nesse contexto, este trabalho fornece dados que corroboram eventuais efeitos deletérios ocasionados aos animais submetidos a esse procedimento cirúrgico.

O uso de porta agulhas e/ou pinças foi considerado inadequado ao sistema de autotravagem, visto promoverem deformidade e inviabilizarem o sistema de trava (COSTA NETO et al., 2006). A exemplo do efetuado por Miranda et al. (2006), utilizou-se pinça hemostática para facilitar e dar mais pressão no fechamento das abraçadeiras, proporcionando perfeita oclusão.

Utilizando a mesma técnica cirúrgica aplicada no presente estudo e comparando a ligadura dos pedículos ovarianos com abraçadeira autoestática ou fio mononáilon, Lima et al. (2010) não observaram aderências de órgãos internos, por exame laparoscópico efetuado aos 60 dias de pós-operatório. De forma similar, no atual estudo não foram observadas pela avaliação macroscópica aderências dos órgãos internos nos três períodos avaliados, ou seja, 30, 60 e 90 dias de pós-operatório. Contudo, observaram-se aderências do omento maior aos pedículos.

A adesiogênese do omento maior em locais de traumas pós-cirúrgicos colabora para redução ou prevenção de aderências a esses locais por outros órgãos, ao mesmo tempo de que desempenha papel crucial na revascularização de lesões nas serosas viscerais (HENDERSON, 1996). No presente estudo as aderências omentais notadas nos três períodos de avaliação ocorreram somente nos sítios de manipulação, possivelmente em consequência da injúria mecânica e isquêmica tecidual causada pela presença da abraçadeira autoestática. Essas observações estão em concordância com os achados de Del Carlo et al. (1997) que, ao promoverem diferentes tipos de lesões em peritônio parietal em cães, verificaram aderências entre o omento e as lesões induzidas, sendo as áreas isquêmicas as maiores contribuintes na gênese das aderências.

O exame histológico mostrou, no presente estudo, presença de reação inflamatória dos sítios de ligadura dos pedículos ovarianos, que foi mais intensa no $30^{\circ}$ dia de pós-operatório. Contudo, aos 30 e 60 dias de pós-operatório foram detectados polimorfonucleares, sugerindo persistência do processo inflamatório. Como referido por Ringler (2000), na sequência fisiológica de um processo de cicatrização, a fase inflamatória aguda é que tem por característica a abundância de polimorfonucleares. Por sua vez, ao compararem o uso das abraçadeiras de náilon e mononáilon na ovariosalpingohisterectomia em cadelas, Lima et al. (2012) observaram, aos 60 dias de pós-operatório, reações similares entre os métodos.

Havia neovascularização, tecido de granulação e células inflamatórias, especialmente mononucleares, porém com presença de polimorfonucleares no grupo da abraçadeira. Neste estudo, somente na avaliação aos 30 dias de pós-operatório foi notada presença de tecido de granulação (60\%) e de neovascularização (50\%).

Reações granulomatosas em quatro casos de complicações com abraçadeiras de náilon foram relatadas da literatura, sendo que em um dos casos havia lacres com extremidades pontiagudas nocivas. A presença de granuloma foi detectada em um animal aos 60 dias de pós-operatório e, aparentemente, não tinha relação com o excedente da abraçadeira, visto a secção ter sido realizada de forma precisa com alicate de aço inox, não deixando extremidades pontiagudas ou arestas.

$\mathrm{Na}$ evolução de um processo cicatricial, os macrófagos e fibroblastos em abundância expressam a fase de proliferação, e a formação de tecido conjuntivo em fase de modelação e maduro são característicos da fase de maturação e remodelamento (RINGLER, 2010). Isso correspondeu aos achados com 90 dias de pósoperatório, ou seja, tecido conjuntivo maduro totalmente organizado com áreas em modelação, macrófagos e linfócitos.

Células gigantes tipo corpo estranho, embora raras, foram detectadas em todos os períodos de avaliação no presente estudo. Isso diferiu do observado por Sorbello 
et al. (1999) que, ao implantarem abraçadeiras de náilon esterilizadas com óxido de etileno em ratos, não detectaram presença de granuloma por corpo estranho.

Por outro lado, uma reação granulomatosa extensa, que favoreceu o desenvolvimento de hidronefrose, foi atribuída ao uso da abraçadeira de náilon em ovariohisterectomia (MESQUITA et al., 2015). Desta forma, a despeito da facilidade do uso do material em campanhas de castração, deve-se considerar que se houver reação intensa ao material há possibilidade de graves complicações ao animal.

Com base nos achados obtidos foi possível concluir que as abraçadeiras promovem reação inflamatória, portanto, existe a possibilidade de provocar aderências em órgãos abdominais. Sendo assim, a utilização desse método deve ser desaconselhada em campanhas de castração, mesmo que implique em baixo custo e menor tempo cirúrgico.

\section{Agradecimentos}

Ao Programa de Pós-graduação em Saúde e Produção Animal na Amazônia e à Coordenação de Aperfeiçoamento de Pessoal de Nível Superior CAPES, pelo apoio financeiro por meio do Programa de Cooperação Acadêmica - Novas Fronteiras (PROCADNF) estabelecido entre UFRA-UFRPE-UNESP Botucatu.

\section{Referências}

ATAIDE, M. W.; BRUN, M. V.; BARCELLOS, L. J. G.; BORTOLUZZI, M.; FERANTI, J. P. S.; SANTOS, F. R.; TOMAZZONI, F.; BRAMBATTI, G.; ZÍLIO, P. P.; ORO, G.; SARTORI, L. W.; MONTEIRO, A. R.; ZANELLA, R. Ovariosalpingohisterectomia vídeo-assistida ou convencional em cadelas com o uso de ligasure atlas. Ciência Rural, Santa Maria, v. 40, p. 1974-1979, 2010.

BARROS, B. J.; SANCHES, A. W.; PACHALY, J. R. Utilização de abraçadeira de náilon 6.6 (poliamida) como método de ligadura de pedículos ovarianos e coto uterino em ováriohisterectomia eletiva em cadelas (Canis familiaris). Arquivos de Ciências Veterinárias e Zoologia da UNIPAR, Umuarama, v. 12, p. 47-60, 2009.
COSTA NETO, J. M.; TEIXEIRA, E. M.; FERREIRA FILHO, E. M.; TORÍBIO, J. M. M. L.; ALMEIDA FILHO, C. H. R.; MORAES, V. J. Braçadeiras de náilon para hemostasia preventiva na ovariosalpingohisterectomia em gatas. Revista Brasileira de Saúde Produção Animal, Salvador, v. 10, p. 615-624, 2009.

CRMV-SP - CONSELHO REGIONAL DE MEDICINA VETERINÁRIA DE SÃO PAULO. Parecer técnico de 15 de abril de 2015. 2015. Disponível em: <http://www.crmvsp.gov.br/site/ noticia_ver.php?id_noticia $=5463>$. Acesso em: $18 \mathrm{fev}$. de 2016 .

DEL CARLO, R. J.; GALVÃO, S. R.; TINTO, J. J. R.; PONTINI, A. C. G.; LOPES, M. A. F. Estudo macroscópico das aderências peritoneais provocadas experimentalmente em cães. Ciência Rural, Santa Maria, v. 27, p. 273-278, 1997.

HENDERSON, R. A. Formação de aderências. In: BOJRAB, M. J. (Ed.). Mecanismos da moléstia na cirurgia dos pequenos animais. 2 ed. São Paulo: Manole, 1996. p. 133-138.

LIMA, A. F. M.; LUNA, S. P. L. Some causes and consequences of canine and feline overpopulation: chance or negligence? Revista de Educação Continuada em Medicina Veterinária e Zootecnia do CRMV-SP, São Paulo, v. 10, p. 32-36, 2012.

LIMA, A. F. M; LUNA, S. P. L.; RODRIGUES, M. M. P.; QUITZAN, J. G. Avaliação histológica e videolaparoscópica de ligaduras dos pedículos ovarianos realizados com mononáilon agulhado ou abraçadeiras auto-estáticas de náilon em cadelas submetidas à ovariossalpingohisterectomia pela técnica do gancho. Ars Veterinária, Jaboticabal, v. 26, p. 66-70, 2010.

MAHLOW, J. C.; SLATER, M. R. Current issues in the control of stray and feral cats. Journal of the American Veterinary Medical Association, Schaumburg, v. 209, p. 2016-2020, 1996.

MESQUITA, L. R.; RAHAL, S. C.; MATSUBARA, L. M.; MAMPRIM, M. J.; FOSCHINI, C. R.; FARIA, L. G.; KANO, W. T. Bilateral hydronephrosis and hydroureter after ovariohysterectomy using nylon cable tie: a case report. Veterinary Medicine, Lenexa, v. 60, n. 1, p. 52-56, 2015.

MIRANDA, A. H.; SILVA, L. A. F.; TAVARES, G. A.; AMARAL, A. V. C.; MIRANDA, H. G. Abraçadeira de náilon: resistência à tração em testes físicos e seu emprego como cerclagem no fêmur de cães. Ciência Animal Brasileira, Goiânia, v. 7, p. 299-307, 2006.

RINGLER, D. J. Inflamação e reparo. In: JONES, T. C.; HUNT, R. D.; KING, N. W. Patologia veterinária. 6. ed. São Paulo: Manole, 2000. p. 119-166.

SORBELlO, A. A.; GUIDUGLI NETO, J.; ANDRETTO, R. Alternativa para ligadura em cirurgias videoendoscópicas ou convencionais, com emprego de fitas de nylon, em estudo experimental. Revista do Colégio Brasileiro de Cirurgia, Rio de Janeiro, v. 26, p. 24-26, 1999. 